\title{
Waning influence provokes green groups' frustration
}

The prospect of a global treaty on greenhouse gas emissions represents - at least in principle - a hard-won victory for the environmentalist movement. Indeed, for groups such as Greenpeace and the World Wide Fund for Nature, Kyoto should be pay day after more than a decade of campaigning. Why, then, is the mood in the green corner one of despair, frustration and anger?

Much is due to the fact that the treaty in sight is much weaker than the one they have been fighting for. Although such groups are sufficiently experienced to know that the final outcome of international negotiations will always fall short of their demands, they are angry that the likely result at Kyoto will be even less than their worst expectations, says Tessa Robertson of Greenpeace International.

One reason, according to some environmentalists, is that Kyoto is unlike several previous meetings on environmental issues including the 1992 Earth Summit in Rio, at which the most governments had to do was to put their names to a set of vague promises on protecting the world's climate. A second reason is that the environmentalist movement is divided. These divisions have made more difficult the task of influencing key governments in the negotiations.

In general, the political power of environmentalist groups in international negotiations rests on their ability to influence pivotal governments from both developed and developing countries. A close understanding is critical to their efforts to shape the outcome of such negotiations, in which they are officially only observers, not participants.

During meetings such as Kyoto, 'green' activists regularly exchange information in private with friendly governments, and pass on selected - and measured - snippets of information to those who they can trust or, such as journalists, help to spread their message. Friendly governments are provided with useful items of gossip; less friendly governments are aggressively lobbied during lunch-breaks and in the corridors.

"Information is our greatest asset. It is our greatest source of strength. It is where our power lies," says Delia Villagrasa, director of Climate Network Europe in Brussels. "We don't have the money, but we do have access to the main players."

At Rio, environmentalists were close to countries such as Canada and India, both of which assumed strong and influential leadership positions in discussions on the climate convention. But changes in government in both countries mean that neither can be relied upon to support the environmentalist cause.
Not all has been lost. Canada's role has, to some extent, been replaced by the more powerful European Union, and in particular by Britain, whose greenhouse target is one of the toughest on the table, and closest to the environmentalists' demand of a 20 per cent reduction in emissions by 2005.

But India's role has been harder to replace. Indeed, its loss means that the greens now lack an ally among the 'influential developing countries'; the long-standing support of the 42-member Alliance of Small Island States is not enough. The environmentalists need a big hitter.

\section{One priority or many?}

An African country might have played this part. But a split in the environmentalist movement has meant that Africa's loyalties have been pledged elsewhere to another environmentalist group. This may sound like routine activist infighting, but it has important implications for the outcome at Kyoto. And it cuts to the heart of the debate about the nature of environmentalist activism.

Environmentalist groups fall into two broad categories. There are those, such as Greenpeace and other members of the broad Climate Action Network (CAN), for whom protecting the environment will always remain a priority above all else. They argue that human survival demands deep cuts in emissions - and that nothing less will do.

But there are others, particularly in developing countries, for whom environmental protection is part of a wider agenda to reduce poverty and increase 'quality of life.' "The old debate of environment versus development is irrelevant," says Aban Marker Kabraji, regional director for south and southeast Asia at the International Union for the Conservation of Nature. "Issues of poverty alleviation, governance, and the economy are as important as the latest statistics on sea level rise."

Integrating environment with development is an attractive way of 'selling' environmental awareness to developing countries. It was sufficient to convince Rungano Karimanzira, leader of Zimbabwe's delegation to Kyoto, and deputy director of the country's Department of Meteorological Services, not to support CAN on the question of per capita emissions (see page 217). As Zimbabwe happens to head the group of African countries, the rest of the continent took little persuading to follow suit.

For Anil Agarwal, director of the Centre for Science and Environment in New Delhi, CAN's failure to influence more governments boils down to its unwillingness to see climate change in a broader context. "[Environmentalist] non-governmentalist organizations lost the plot after Rio," says Agarwal. He says they restricted themselves to campaigning for reduced emissions when they should have worked out detailed positions on related issues, and then tried to sell their ideas to governments.

E.M.

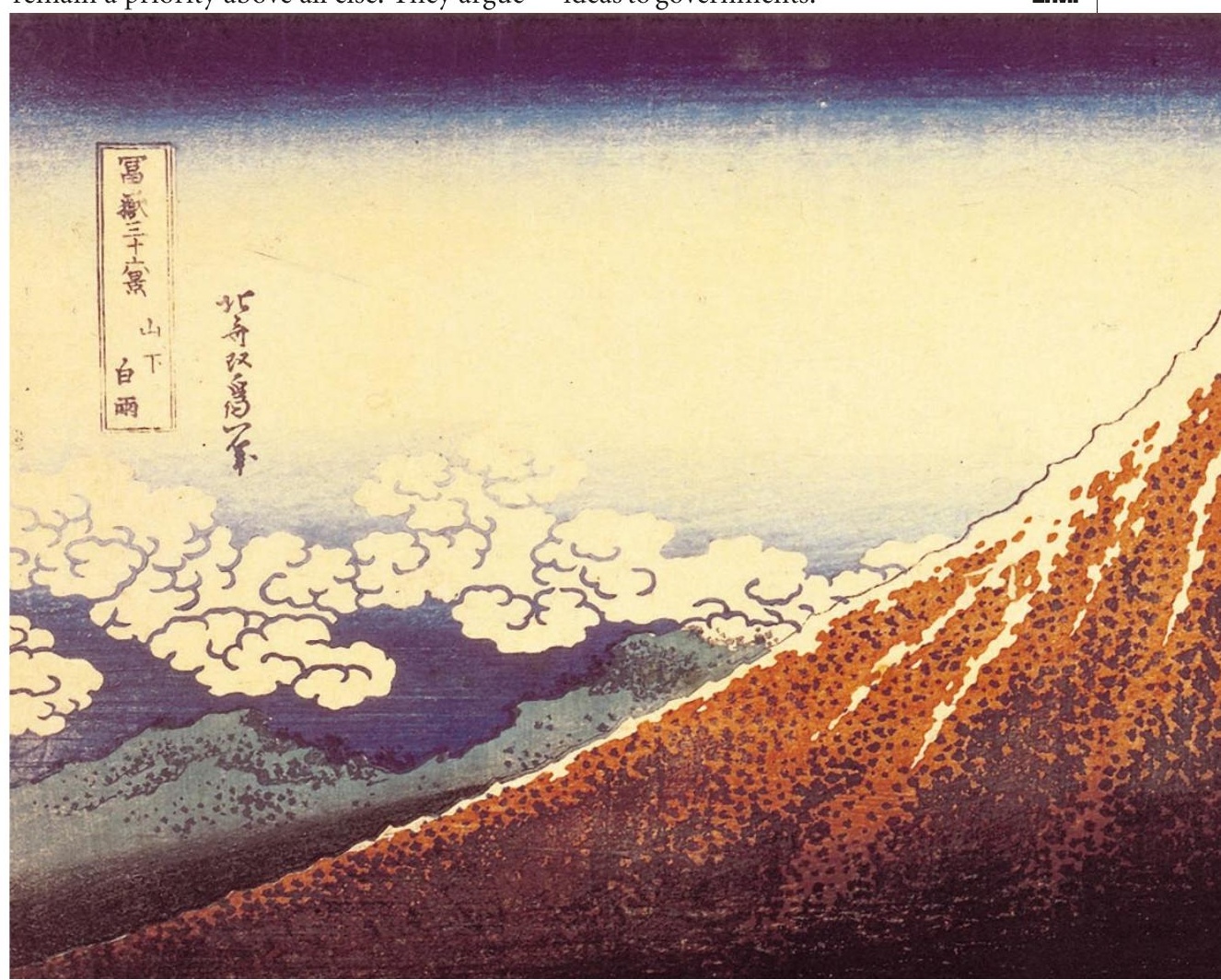

